解 説

\title{
磁気コセラ連続体理論と磁性粒子の磁場中成形時の配向挙動解析
}

\author{
小寺 秀俊, 島進 \\ 京都大学大学院工学研究科機械工学専攻, $\mathrm{T}$ 606-8501 京都市左京区吉田本町.
}

\section{A Study of Magneto-Cosserat Theory to Simulate Powder Behaviour during Compaction}

\section{Hidetoshi Kotera and Susumu Shima}

Kyoto Univ., Yoshida Honmachi Sakyo-ku, Kyoto 606-8501.

Received December 25, 1998

\begin{abstract}
SYNOPSIS
Numerical method based on the Cosserat continuum theory is proposed for simulation of a magnetic powder in an applied magnetic field. The Maxwell stress is induced in the magnetic powder. During powder forming process in the magnetic field, the magnetic particles are thus rotated and transferred by both mechanical and magnetic interaction. To simulate this powder behavior, new finite element method considering Maxwell is formulated on the basis of the Cosserat continuum theory of compressible plasticity. The powder behavior with magnetic alignment during compaction in magnetic field is simulated by the proposed method to discus the effect of couple-stress on the powder behaviour. The relationship between the direction of magnetic field and the compaction process can be also analyzed: difference of magnetization in cross compaction, transverse compaction and isostatic compaction. In the calculation, the directions of the easy axes are given by a set of random numbers. The rotation of the axes is thus calculated at various conditions of applied magnetic field. The results are discussed comparing with those by particle dynamics simulation.
\end{abstract}

KEY WORDS

magnetic powder, Cosserat continuum theory, finite element method, compaction

\section{1 緒言}

機械部品や電気部品の多くが, 粉末を種々の方法で成形さ れることにより製造されている。粉体を成形する場合，成形 後の密度分布, あるいは成形体の寸法精度や形状精度および その電気的特性等を考慮することが重要である，例えば永久 磁石は, 異方性磁性粒子からなる磁性粉体を磁場中で成形す ることで作成される，永久磁石は，電動機のみならず医療用 機器や情報機器における重要な基幹部品である。磁性粒子は 磁場中で圧粉されることで，かけられた磁場の强さおよび方 向により配向する，磁性粒子は磁場中に置かれると着磁する が，着磁した粒子は粒子間に作用するクーロン力により互い に結合し，粒子鎖を生じる。この粒子鎖が圧粉されると，粒 子間に作用する機械的な作用力と磁気的な作用力により，粒 子は回転と並進することで再配置する。このように，磁性粒 子を磁場により配向させることで圧粉体は磁気特性を示すが, 外部磁場の方向と圧粉方向の関係により, 圧粉後の粒子の配
向方向が強く影響されると考えられる．粒子の配向挙動は， 粒子の形状と粒子の磁化容易軸の方向との関係に依存するが, 長手方向に磁化容易軸を持つ針状粒子の場合には，磁場の方 向と圧粉方向が直行している場合の方が磁場と同じ方向に圧 粉した場合よりも，磁化容易軸が粒子の外部磁場方向への配 向が高くなる傾向にあると一般的に認識されている.しかし， 圧粉中の磁性粒子の配向挙動に関しては，明確にはなってお らず，磁場中成形における粒子挙動の解明が必要である。粉 体の成形時における密度分布や形状に関する力学的なシミュ レーションは，有限要素法を用いて行われてきたが，磁場の 影響を考慮することが必要であるため，磁性粒子からなる粉 体を磁場中で圧粉成形する場合の粒子挙動を解析することは 不可能であった．著者らおよび田村らが提案した個別要素法 に基づく方法は，磁性粒子の磁場中成形時における粒子挙動 をシミュレーションすることが可能である 2-8). しかし，個別 要素法に基づくシミュレーション手法では, 粒子個々の挙動 
をミクロな視点から明らかにすることは可能であるが粉体全 体における配向分布を求めることは，計算時間および計算機 の記憶容量の面から困難である。そこで, 粉体全体の挙動と 粒子個々の挙動の両方を解析することが可能な新たな解析方 法を考案することが必要であるため，従来からその有効性が 明らかであり，広く使われている連続体理論に基づく解析理 論に，外部磁場および磁化した粒子個々の局所回転を考慮で きる新たな連続体理論を導出し，それに基づく解析手法の研 究が行われている.

コセラ連続体理論は連続体理論に偶応力による反対称の応 カテンソルを取り入れることで，連続体内で局所回転を考慮 することを可能にした理論である。この理論を応用すること によって，粒子の回転を考慮して粉体の挙動を解析すること が可能であると考えられる.Lippmanらはコセラ連続体理論 を塑性変形に拡張し ${ }^{9.10}$, さらに, 森らは粉体の塑性変形挙動 の解析理論を提案している ${ }^{11}$. 我々は，粉体の塑性変形を考 慮したコセラ連続体理論に，外部磁場により磁性粉体内部に 生じるマクセルの心力を考慮した磁気コセラ連続体理論を利 用して，磁性粒子からなる粉体の磁場中成形時における各粒 子の磁化容易軸の配向挙動と圧粉成形方法との関係について 解析するための，モデル化手法を提案し，それを用いた解析 結果についてこれまでの個別要素法による結果と比較しなが ら考察した ${ }^{12,13)}$. 本稿では, 磁気コセラ連続体理論とそれを用 いた解析結果について解説する。

\section{2 磁化コセう連続体理論}

外部磁場により磁性粉体内部に生じるマクセルの応力を考 慮した粉体の塑性変形の支配方程式を示し，有限要素法を用 いて解析する方法について簡単に説明する ${ }^{13)}$.

磁性粉体が磁場中に置かれた場合，粉体を形成する個々の 磁性粒子は外部磁場および他の粒子が外部磁場により分極す ることで生じる磁場の影響を受けて磁気分極する。磁気分極 した粒子は互いに反発または引き合う。この作用力はマクセ ルの応力 $T_{i j}$ として, 次式で定義される.

$$
T_{i j}=H_{i} B_{j}-E_{i} D_{j}-\delta_{i j} U^{e m}, U^{e m !}=\frac{1}{2} H_{i} B_{j} .
$$

ここで, $B_{j}=\mu H_{j}+M_{j}$ であり， $\mu H_{i}$ は磁場 $H_{i}$ が媒質を通過すると きの磁束を表しており，Mi物質の磁気分極である，

マクセルの応力は物体力として粉体に作用するので, 粉体の微 小領域における応力の平衡方程式は次式のように記述できる.

$$
\frac{\partial \sigma_{i j}}{\partial x_{j}}+\frac{\partial \tau_{j i}}{\partial x_{j}}+\frac{1}{2}\left(M_{j} \frac{\partial H_{j}}{\partial x_{i}}-H_{j} \frac{\partial M_{j}}{\partial x_{i}}\right)=0
$$

なお，ここでは，磁場は静磁場とし磁性粉体内部に渦電流は 流れないと考える. 圧粉成形時には粒子は他の粒子の変形と 並進および回転により並進および回転する。ささらに，磁性粒 子が外部磁場により生じた磁性粉体内部の磁気分極中にある 場合，磁性粒子はその粒子が置かれた磁場の作用により回転 する。すなわち，粒子は他の粒子との接触による回転・並進
作用力を受けるのみならず，磁場により回転する。この結果， 粒子の集合体である粉体を連続体としてとらえた場合，粉体 内部のせん断ひずみは反対称成分をもつ、そこで応力テンソ ルを対称部分と反対称部分に分解し，前者を $\sigma_{i j}$, 後者を $\tau_{i j}$ で あらわした．また，この反対称成分を生じる偶応力 $m_{i j}$ との回 転に対する平衡方程式はマクセルの応力を考慮して次式とな 万.

$$
\frac{\partial m_{j i}}{\partial x_{j}}+\varepsilon_{i j k} \tau_{j k}+\varepsilon_{i j k} M_{j} H_{k}=0
$$

ここで， $\varepsilon_{i j k}$ は交代記号である。

塑性ポテンシャル $F$ は次式のように定義する ${ }^{11.13}$.

$$
\begin{aligned}
& F=\frac{3}{2} \sigma_{i j}^{\prime} \sigma_{i j}^{\prime}+3 \beta \tau_{i} \tau_{i}+\frac{3}{2 l^{2}} m_{i j} m_{i j}+\left(\sigma_{m} / f\right)^{2}-\left(\rho^{\prime \prime} \overline{\bar{\sigma}}\right)^{2}, \\
& f=\frac{1}{a(1-\rho)^{m}}, \tau_{i}=\frac{1}{2} \varepsilon_{i j k} \tau_{j k} .
\end{aligned}
$$

$\rho$ は粉体の密度比， $a, n, m, \bar{\sigma}$ は実験により決まるパラメー

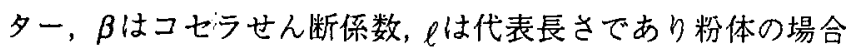
には平均粒径とするのが妥当である.コセラせん断係数 $\beta$ は せん断応力の非対称成分の対称成分に対する割合であり，粒 子の自転 $\omega$ 及び粉体の回転がせん断応力の非対妳性に及ぼす 影響を示している。すなわち，コ七ラせん断係数 $\beta$ は粒子の 自転の影響を強く受け，粒子の形状・粉体の密度・粉体の降 伏挙動と密接に関係すると考えられる。このコセラせん断係 数の值は, 理論解析または数值奏験や実験により求めること が必要である。

通常の有限要素方程式を定式化するための手順に従い，仮 想仕事の原理より，最小化すべきエネルギー関数 $\Phi$ は次式の ようになる。

$$
\begin{aligned}
\Phi= & \int_{V} \dot{W} d V+\int_{S_{F}} n_{j}\left(\sigma_{j i}+\tau_{j i}\right) u_{i} d s+\int_{S_{M}} n_{j} m_{j} \omega_{j} d s \\
& -\int_{V}\left[\frac{1}{2}\left(M_{k} \frac{\partial H_{k}}{\partial x_{i}}-H_{k} \frac{\partial M_{k}}{\partial x_{i}}\right) u_{i}+\varepsilon_{i j k} M_{j} H_{k} \omega_{i}\right] d V
\end{aligned}
$$

ここでがは, 単位体積あたりのひずみエネルギ一速度である。

$$
\begin{aligned}
& \dot{W}=\sigma_{i j} \dot{\varepsilon}_{i j}+2 \tau_{i}\left(\dot{\gamma}_{i}-\omega_{i}\right)+m_{j i} \dot{\kappa}_{i j} \\
& \dot{\gamma}_{i k}=\frac{1}{2}\left(\frac{\partial u_{k}}{\partial x_{j}}-\frac{\partial u_{j}}{\partial x_{k}}\right), \quad \dot{\gamma}_{i}=\frac{1}{2} \varepsilon_{i j k} \dot{\gamma}_{i k}, \dot{\kappa}_{i j}=\frac{\partial \omega_{i}}{\partial x_{j}}
\end{aligned}
$$

また， $n_{j}$ は解析領域 $S$ 上にある有向面積要素 $d S$ の外向き法線 ベクトルで， $u_{i}$ は変位速度， $\omega_{i}$ は回転角速度である，境界 $S_{F}$ は変位速度が未知そして境界 $S_{M}$ は回転速度が未知の境界であ る.

\section{3 磁性粒子の磁堭中成形時の配向挙動}

本解説では，近年ボイスコイルモータ等に多く利用されて いる Nd-Fe-B 等のような磁化容易軸を持つ磁気異方性粒子か 
らなる磁性粉体を磁場中で圧粉した場合の粒子配向举動を解 析した結果について示す(Fig.1参照)，本来，解析対象とする 粉体について，解析に必要な材料パラメータである $\bar{\sigma}, n, m, a$, $\beta, l$ を求める必要があるが，本解説では Table 1 に示す值を用 いた．奏際の磁性粉体の圧粉時における配向挙動を定量的に 評価するためには，これら6個の材料定数のみならず，粒子 の磁化の強さ $M_{0}$ も対象とする材料ごとに測定して用いる必要 がある.

磁化した粒子モデルとしてFig.2に示す磁化容易軸モデルを 用いる，有限要素の各節点においてそこに位置する粒子が， 図に示すような磁化容易軸を有すると仮定する，磁化容易軸 は本来，外部磁界により粉体内部に分布する磁界により磁化 されかつ周辺の粉体の磁界によりモーメントを受けるが，磁 界の方向は粉体内部で変化しないとする．また，粉体は圧粉 により密度が変化するために, 磁気分極の強さ $M^{\mathrm{x}}$ は粉体の 密度比に比例するとし，次式により定義している．

$$
M^{e x}=\left(M_{x}^{e x}, M_{y}^{e x}\right)=\left(M \cos \theta_{1}, M \sin \theta_{1}\right), M=\rho M_{0}
$$

ここで $M_{0}$ は密度比 1 の場合の磁化の強さであり，㩆は有限要 素の節点ににおける磁化容易軸と外部磁界がなす角度である。

粒子の磁化容易軸が有限要素の節点に粒子の磁化容易軸を 設定することで，連続体と粒状体の両方を考慮することが可 能になる．ランダムに向いている状態を初期状態 (Fig.3(a) 参 照)とし，初期密度比を 0.4，粉末とダイスとの摩擦係数を 0.03 として, $7.95 \times 10^{5} \mathrm{~A} / \mathrm{m}$ の外部磁界をかけながら, 密度比約 0.7 まで圧粉した場合の各節点における磁化容易軸の方向を

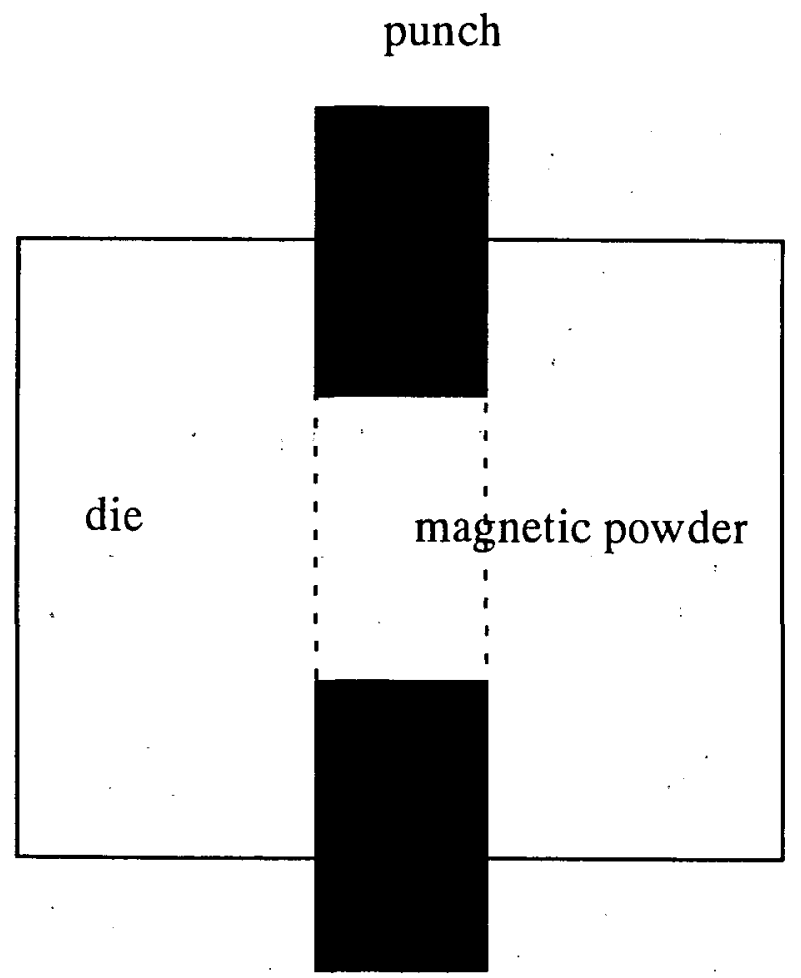

Fig.1 Magnetic powder compaction in closed die.
Fig.3(b)に示す．磁場中で圧粉することで，粒子は外部磁界の 影響を受けて回転していることが分かる．圧粉後の粒子の磁 化容易軸の方向は一様に外部磁界の方向に向くのではなく， 圧粉体内部に磁化容易軸の粒子鎖を作成している，圧粉体表 面においても，磁化容易軸は外部磁場の方向を向いていない． このことは，個別要素法により解析した結果と定性的によく 一致している (Fig.3(c) 参照).

圧粉方向と外部磁界の方向が異なると，磁性粒子の種類に もよるが，圧粉後の磁気特性が異なるということが一般的に 認識されている.そこで，磁場を密度比が $0.4 か ら 0.45$ までか けた場合，平行圧粉・交差圧粉・静水圧圧粉の場合の圧粉後 の磁化容易軸の配向分布解析をした結果をFig.4に示す. 平行 压粉と交差圧粉および静水圧圧粉のいずれの圧粉方法におい ても，磁化容易軸は磁場をかけている密度比 0.45 までは外部 磁界の方向に回転し，磁場が零になった以降はほとんど回転 していない，平均配向角は，静水圧压粉，交差圧粉，平行圧 粉の順に小さくなっており，その差はそれぞれ 5 度程度で あった。これは，定性的には個別要素法による結果2のとよく 一致しており，一般に実験に扔ける認識とも一致している。

Table1 Material parameters and other conditions for simulation.

\begin{tabular}{|c|c|}
\hline Initial density ratio $\rho_{0}$ & 0.4 \\
\hline$\beta$ & 1.0 \\
\hline Representative length $\ell$ & $0.01 \mathrm{~mm}$ \\
\hline Friction coefficient & 0.0 \\
\hline$f$ & $1 / 2.5(1-\rho)^{0.51}$ \\
\hline$\sigma$ & $10,200 \mathrm{MPa}$ \\
\hline $\mathrm{M}_{0}$ & $0.7 \mathrm{~Wb} / \mathrm{m}^{2}$ \\
\hline
\end{tabular}

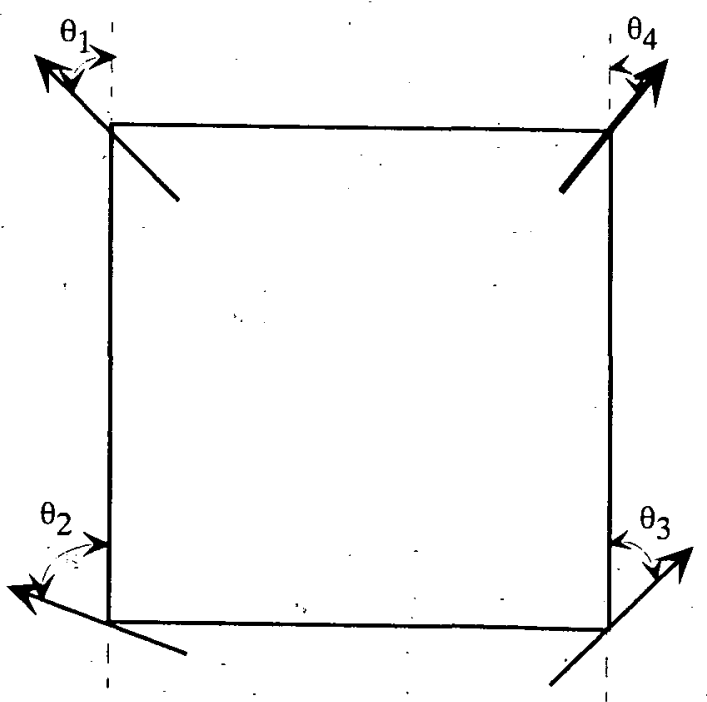

Fig.2 Model for easy axis at finite element node. 


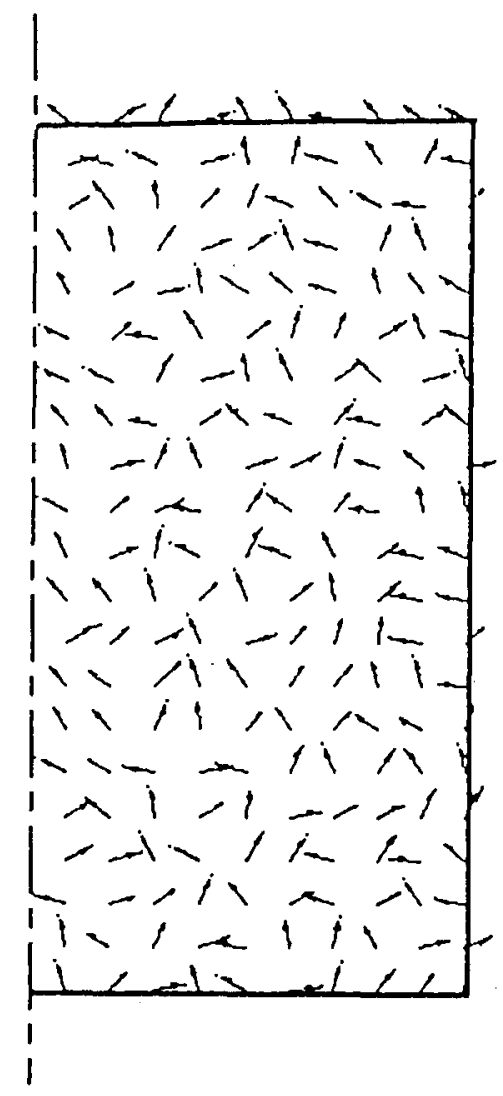

(a) Initial direction of easy axisfor Cosserat theory

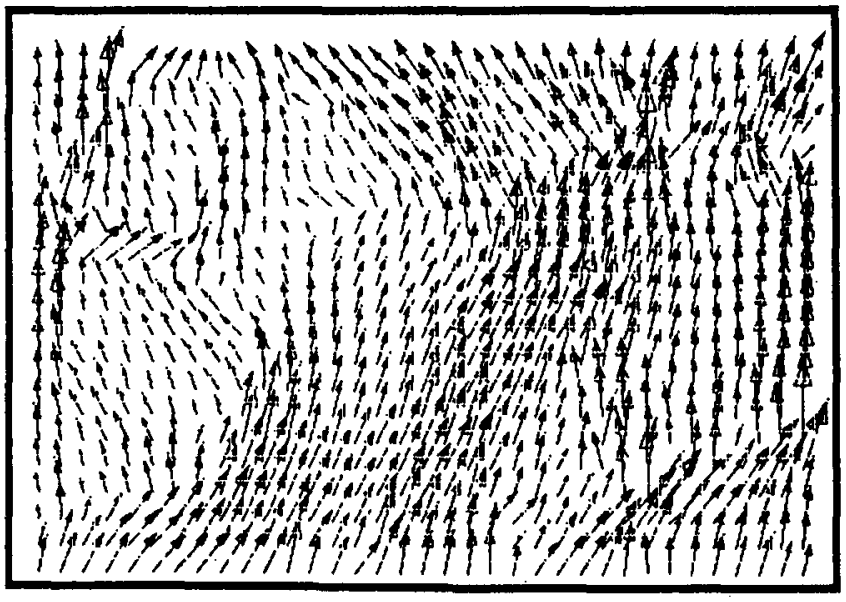

(c) Distribution of particle'seasy direction of magnetization calculated by particle dynamics method.

Fig.3 Distribution of easy direction of magnetization for each paticle.

Fig.5は，磁場をかけ始める密度と磁化容易軸の回転角度の 関保を示したグラフである，初期密度を0.4とし，最初から磁 場をかけた場合, 密度比0.5まで圧粉した後に磁場をかけた場 合，同様に0.6,0.7まで磁場をかけずに予備圧粉した場合の結 果である，粒子は磁場をかけた直後に大きく回転し，その後

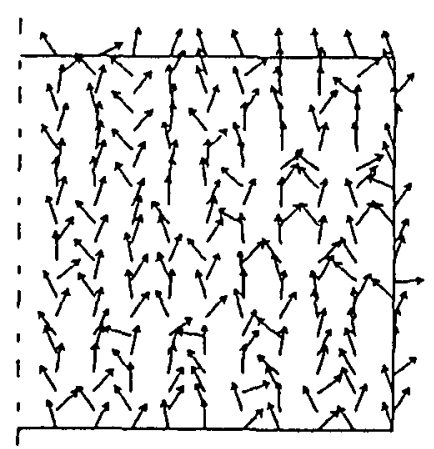

H

(b) Direction of easy axis after compaction by Cosserat theory

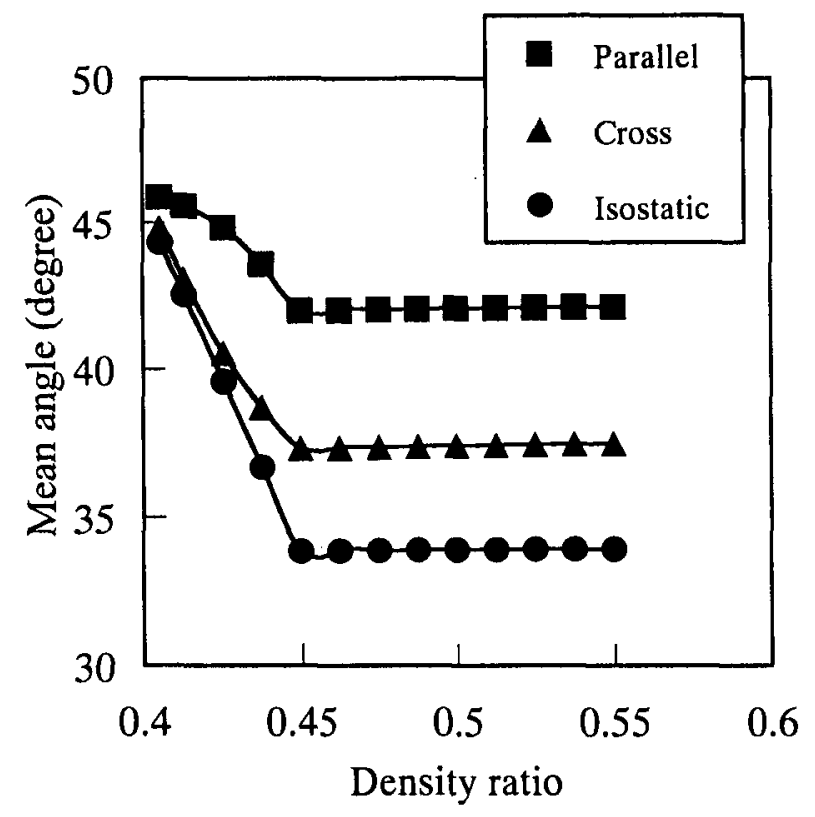

Fig.4 Rotation of easy axis of magnetization V.S. relative density (Magnetic field, $\mathrm{H}=7.95 \times 10^{-5} \mathrm{~A} / \mathrm{m}$, is applied from 0.4 upto 0.45 ).

粒子の回転量は減少していくままた，磁場をかけ始める密度 が高いほど，回転角度は小さくなっている。これは，磁性粒 子の回転は粒子が受ける機械的な応力が，外部磁界およびマ 


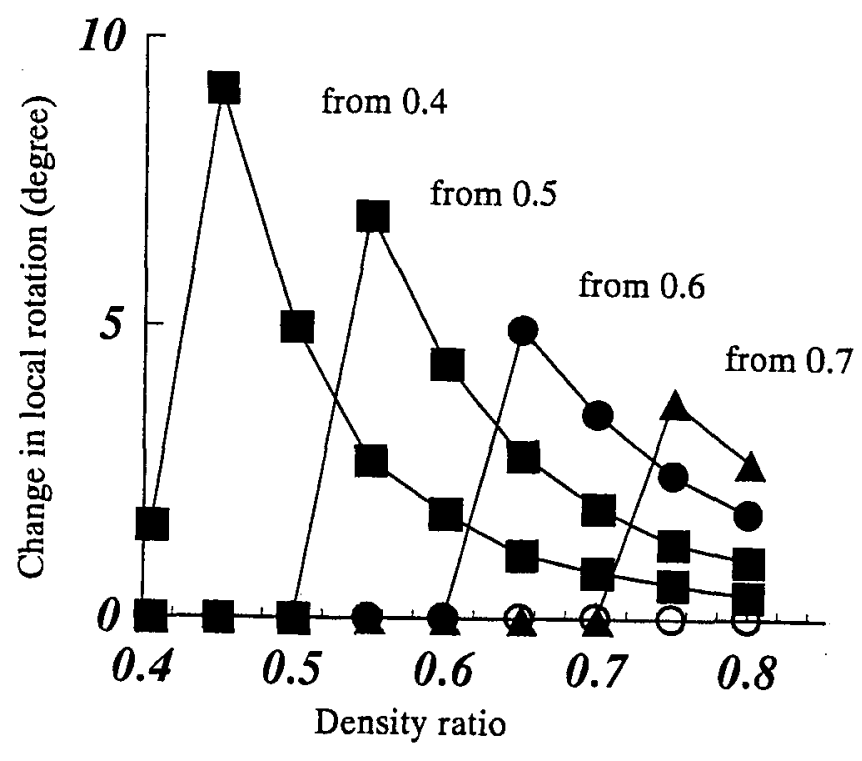

Fig.5 Effect of powder density on the particle rotation.

クセルの応力により粒子が受けるモーメントに対して抵抗力 となるために，密度が高いほど回転量が減少するためと考え られる。

\section{4 結 言}

本稿では，磁性粒子を磁場中で圧粉成形する場合の粉体挙 動特に, 粉体を構成する磁性粒子の磁化容易軸の配向挙動を， 磁気コセラ理論により平面ひずみ場において解析する理諭に ついて解説するとともに圧粉方向と磁場の方項の関保につい て解析した結果について示した。これらの結果から, 磁気コ 七ラ連続体理論が磁性粒子の磁場中成形時における磁化容易 軸の配向解析に有効であると言える。

\section{謝辞}

本研究の一部は, 文部省科学研究費補助金 基盤研究 (B)(2) (課題番号:08455334)及び社団法人粉体粉末治金協会の「萌芽 的研究助成金」の援助により行ったっここに謝意を表します.

\section{文献}

1) M.Sagawa and H.Nagata: "Novel Processing Technology for Permanent Magnets", IEEE Transactions on Magnetics, 29(1993) 2747-2751.

2) S.Tamura, T.Aizawa and K.Kihara: GRANULAR MODELING SIMULATOR FOR POWDER COMPACTION PROCESSES. Advances in Powder Metallurgy \& Particulate Materials (compiled by J.M.Capus \& R.M.German), Metal Powder Ind. Fed., Princeton, NJ, 2(1992)29-41.

3) H.Kotera, H.Kitahara, A.Onoyama and S.Shima: "Behavior of Magnetic Particles in Compaction", IEEE Transaction on magnetics, 33(1997)1616-1619.

4) H.Kotera, H.Kitahara, A.Onoyama and S.Shima: "Behavior of magnetic particles under compaction", ISPS-Vol.1, Advances in Information Storage and Processing Systems ASME, (1995)135139.

5) H.Kotera, H.Kitahara and S.Shima: "PARTICLE DYNAMICS SIMULATION FOR BEHAVIOR OF ELLIPTICAL PARTICLES", Advances in Powder Metallurgy \& Particulate Materials, (1996)7-101.

6) H.Kotera, A.Onoyama and S.Shima: "Behavior of Ferromagnetic Granular in Magnetic Field and Magnetic Characteristics of Compact by Particle Model", Journal of the Japan society of Powder \& Powder Metallurgy, 42(1995)645-650.

7) H.Kotera, H.Kitahara and S.Shima: "Non-circular Particle Behavior under Compaction in Applied Magnetic Field", Journal of the Japan society of Powder \& Powder Metallurgy, 42(1995) 1019-1026.

8) H.Kotera and S:Shima: "A study of Relationship Between Density Distribution and Magnetic Flux in Magnetic Field Compaction". Advances in Powder Metallurgy \& Particulate Materials, 6 (1994)39-49.

9) Bogdanova-Bontcheva and Lippmann: "Rotationssymmetrisches ebenes Frießen eines granularen Modellmaterials", Acta. Mechanica , 21(1975)93-113.

10)R. de Borst and L.J.Sluys: "Localisation in a Cosserat continuum under static and dynamic loading conditions", Computer Methods in Applied Mechanics and Engineering, 90(1991)805-827.

11) K.Mori, M.Shiomi and K.Osakada: "Inclusion of microscopic rotation in rigid-plastic finite element analysis method using Cosserat continuum theory", Advanced in Engineering Plasticity and its Applications, Pergamon, (1996)741-746.

12) H.Kotera, M.Sawada and S.Shima: "COSSERAT CONTINUUM THEORY TO SIMULATE COMPACTION OF MAGNETIC POWDER IN APPLIED MAGNETIC FIELD", Mechanical Science, (1999), to be published.

13)S.Shima, T.Inoue, M.Oyane and K.Okimoto: "Study on Compacting of Metal Powders (2nd Report) (Investigation of compaction criterion by three dimensional compaction) ", Journal of the Japan society of Powder \& Powder Metallurgy, 22(1976) 257-263. 